\title{
Increasing Tree Cover in Degrading Landscapes: 'Integration' and 'Intensification' of Smallholder Forest Culture in the Alutilla Valley, Matiranga, Bangladesh
}

\author{
Syed Ajijur Rahman • Md Faizar Rahman • \\ Terry Sunderland
}

Accepted: 20 September 2013/Published online: 27 September 2013

(C) Steve Harrison, John Herbohn 2013

\begin{abstract}
Research was conducted in Alutilla Valley in eastern Bangladesh to identify the nature of existing agroforestry systems and to identify potential agroforestry models that could ameliorate currently degrading forest resources Data were collected through farmer participatory research and a structured quarterly survey in two villages. Qualitative and supplementary quantitative analysis methods were used to assess the financial potential of agroforestry systems. Various patterns of agroforestry exist in the study site, but all have two common principles, namely 'integration with agriculture' and 'multi-functionality'. Two agroforestry models suitable for adoption by farmers have been identified. Multi-strata agroforestry, based on a fruit and timber tree canopy with vegetables and tuber species in the understorey, can be practiced in the shifting cultivation fields near settlements. Fruit and timber tree-based conservation agroforestry is well suited to manage large-scale biologically depleted landscapes. Both systems yield early financial returns, facilitating the change from shifting cultivation to multi-strata agroforestry or fruit and tree-based conservation agroforestry.
\end{abstract}

Keywords Shifting cultivation - Deforestation · Agroforestry · Forest management $\cdot$ Livelihoods

S. A. Rahman (凹) - T. Sunderland

Center for International Forestry Research (CIFOR), Bogor Barat 16680, Indonesia

e-mail: sumonsociology@yahoo.com

S. A. Rahman

Forest and Landscape, University of Copenhagen, 1958 Frederiksberg, Denmark

S. A. Rahman

School of Environment, Natural Resources and Geography, Bangor University,

Bangor LL57 2UW, UK

M. F. Rahman

Department of Sociology, University of Rajshahi, Rajshahi 6205, Bangladesh 


\section{Introduction}

Landuse change and deforestation account for $18 \%$ of greenhouse gas (GHG) emissions globally, and $27 \%$ in Asia (Audsley et al. 2009). Aside from deforestation, one of the main landuse challenges in developing countries is to reduce environmental degradation on fragile agricultural land. In south Asia, increasing population pressure, rural poverty, poorly managed crop and animal production and agricultural expansion into marginal land all contribute to serious environmental degradation (Rahman and Rahman 2011).

The Chittagong Hill Tract (CHT) of Bangladesh is facing a serious problem of degradation of land and forests. Although the entire CHT area was covered with dense forest in the early 19th century, most has now been denuded and covered with weeds with some scattered trees and shrubs (ADB 2001). A FAO-supported inventory of the Chittagong Forest indicates that the area of natural forest decreased from 26,114 ha in 1990-16,390 ha in 2005 (FAO 2005).

The degradation of the Chittagong forest has affected the livelihoods of local communities which depend largely on forests to fill their basic subsistence requirements and cash income. Due to extensive shifting cultivation linked to high population growth, agricultural yield has declined in many parts of the CHT and farmers fail to achieve even a subsistence level of production. As a result, poverty, malnutrition and other forms of deprivation are pervasive (UNDP 1994; Huq 2000).

To protect the forest resources from overexploitation by indigenous people, almost the entire CHT forest was nationalized during the British colonial period. The management of these resources was vested with the Forest Department (FD), a bureaucratic institution that represents the central government in the region. Rules and regulations were formalized and codified in Chittagong Hill Tracts Regulation 1900 and the Forest Act 1927. However, forest commons are still degrading in the CHT, while the state through local government attempts to establish its control over forest resources (Shoaib et al. 1998; Arya 2000; Huq 2000; Gafur 2001; BFD 2008). The history of external intervention in the use and management of land and forests in the CHT is more than two centuries old. The resource use and management can only be fully understood in relation to the political and social processes over access, control and management of resources (Niemeijer 1996; Bryant 1997).

Scientific data show that agroforestry is considered as one of the major strategies for forest conservation and food crop production in Bangladesh and other tropical Asian countries (Mai 1999; Rahman et al. 2007; Leakey et al. 2012). Agroforestry is found not only helpful in increasing food and fodder production but also in protecting the environment through increasing the extent of existing forest where unemployed and poor landless farmers attempt to secure their livelihoods (Elevitch and Wilkinson 1998; Nath et al. 2005). The aim of this research is to identify the nature of existing agroforestry systems, in terms of structure and financial performance, and based on this to suggest a potential agroforestry model that could better manage the degrading forest resource base whilst also meeting the financial needs of farmers in the uplands of Eastern Bangladesh. 


\section{The Study Site}

Two villages-namely Rasulpur and Dashnong in the Alutilla Valley of Matiranga Upazila (a small administrative unit) of Khagrachhari District in the uplands of Eastern Bangladesh — were selected for the study (Fig. 1), primarily because of their remoteness and the crucial role forests play in local livelihoods, as well as long experience of the local people with agroforestry systems.

The study site is part of the Chittagong Hill Tract, the only extensive upland area in Bangladesh which lies in the eastern part of the country, and is between $23^{\circ} 04^{\prime} 56.24^{\prime \prime} \mathrm{N}$ and $23^{\circ} 05^{\prime} 16.1^{\prime \prime} \mathrm{N}$ latitudes and $91^{\circ} 51^{\prime} 53.64^{\prime \prime} \mathrm{E}$ to $91^{\circ} 52^{\prime} 45.16^{\prime \prime} \mathrm{E}$ longitudes. The region has a tropical monsoon climate with mean annual rainfall over 2,540 $\mathrm{mm}$. The hill soils (dystric cambisols) are mainly strongly acidic yellowish brown to reddish brown loams, which degrade into broken shale or sandstone as well as mottled sand (BBS 2007). The vegetation is characterised by semi-evergreen (deciduous) to tropical evergreen forest dominated by tall trees belonging to the families Dipterocarpaceae, Euphorbiaceae, Lauraceae, Leguminosae and Rubiaceae, and a species of grass (Imperata arundinacea) known locally as shan (Bangladesh Bureau of Statistics (BBS) 2007).

\section{Research Method}

Primary data were collected by: direct observation of local cultivation practices; structured interviews with a purposive sampling of 100 households (50 from each village) focused especially on forest products and income; semi-structured interviews with a judgment sample ${ }^{1}$ of 60 households (agroforestry cultivators) focused on the financial benefits of agroforestry; rapid rural appraisal and four focus groups, geared especially towards the nature of forest resource uses, types and vision of agroforestry systems, land tenure and existing market systems. Due to distance from nearest forest and occupational differences, there are various form of forest dependency and uses of NTFPs of the households, thus the sample was selected purposively to include forest-dependent households. Secondary data from statistical yearbooks, local administrative records and local NGOs on natural, socioeconomic and environmental conditions, cultivation practices, forest resource uses and land-use were also collected.

The structured and semi-structured questionnaires were tested with six and three households respectively. A number of questions were refined with the help of respondents, rapid rural appraisal and focus groups. The survey was repeated in four successive quarters to cover a full 12 -month period. The quarterly survey approach was chosen because studies have demonstrated that data accuracy and reliability increase dramatically when the recall period is shortened, particularly for irregular income sources such as forest extraction (Angelsen et al. 2011). Also, farm income often has considerable seasonal variation. Documenting these variations can help to

\footnotetext{
${ }^{1}$ This sampling was based on investigators scientific knowledge and professional judgment to identify agroforestry farms with the criteria of deliberate integration of trees with agricultural crops.
} 


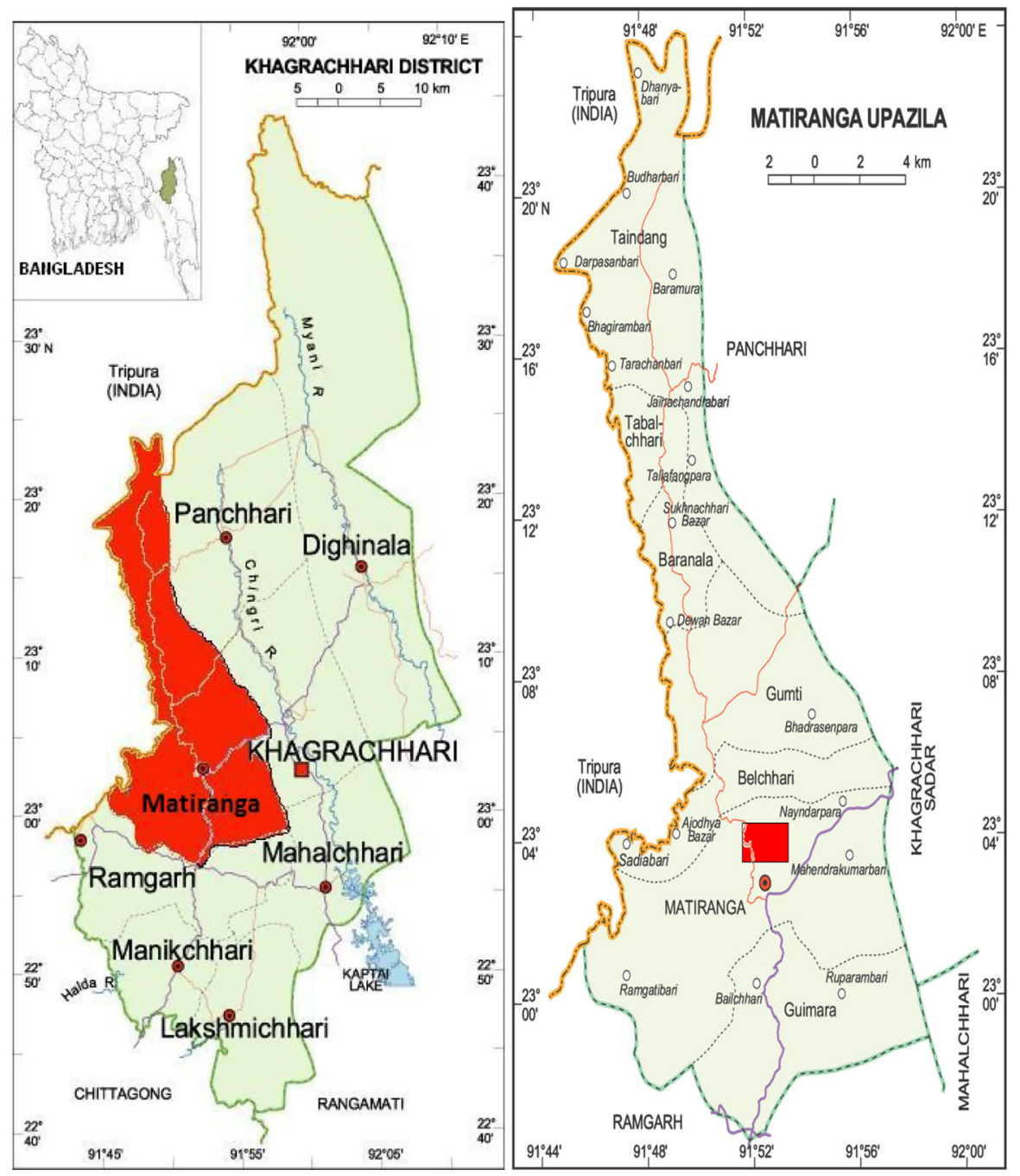

Fig. 1 Location of the study site

understand the extent to which forests act as seasonal 'income gap fillers'. Two research assistants and eight enumerators were employed to conduct the survey, under supervision of researchers, and the response rate was $100 \%$.

\section{Results}

Role of Forests in Rural Livelihoods

Forests provide a wide variety of useful resources for local households in the study area. These resources have a range of economic functions, including sustaining 
consumption, generating cash income, providing inputs for small-scale agricultural enterprises and underpinning capital formation. Forest resources have two different insurance roles: to 'fill gaps' as part of household responses to ex ante risks, such as seasonal and other periodic fluctuations in agricultural goods availability and affordability, and as 'safety nets' as part of household responses to larger ex post shocks, such as drought, unemployment and health shocks.

Forest income (e.g. timber and non-timber forest products) was found to contribute on average $15.9 \%$ of total household income in the study area (Fig. 2), but the average percentage of income varies between seasons (Fig. 3). Forest income (including from direct and value-added products and forest ecotourism) ranked as the third highest contributor $(16.5 \%)$ to household income next to wages (e.g. for agricultural labouring and road construction) $(40.3 \%$ ) and crop income $(31.1 \%)$. Fuelwood, timber, bamboo and rattan are the most important sources of forest income and for cash generation.

Figure 3 presents a distribution of income by season (labelled Q1 to Q4), where total income is high in the wet season (Q1 and Q4) when households can collect fruit including mangoes, jackfruit, pineapples and bananas as well as other NTFPs including wild mushrooms and vegetables. The contribution of forest income is lower than wages and crops, but nevertheless makes an important contribution to household cash income. The main role of forests is supporting current consumptions as a safety net in the form of insurance against crises, such as health needs, and periods when cash is needed (e.g. payment of school fees).

With the decline in timber exploitation due to the disappearance of old growth forest, smallholders have turned their attention increasingly to NTFPs as a financial alternative. They rely heavily on fuelwood and various other NTFPs for food, fodder, medicines and construction materials. Some NTFPs are sold for supplementary household cash income or traded for essentials including rice. Various factors appear to have propelled increasing demand for NTFPs in the study area. There is high demand for products by local, district and national level traders and this trade increased sharply in the late 1990s. For example, the market price of rattan and bamboo increased after developing the road transportation system from the hill tracts to Chittagong district and the capital Dhaka, increasing farmers' access to markets. As well, the increasing price of NTFPs due to increasing demand has made

Fig. 2 Distribution of household income by source

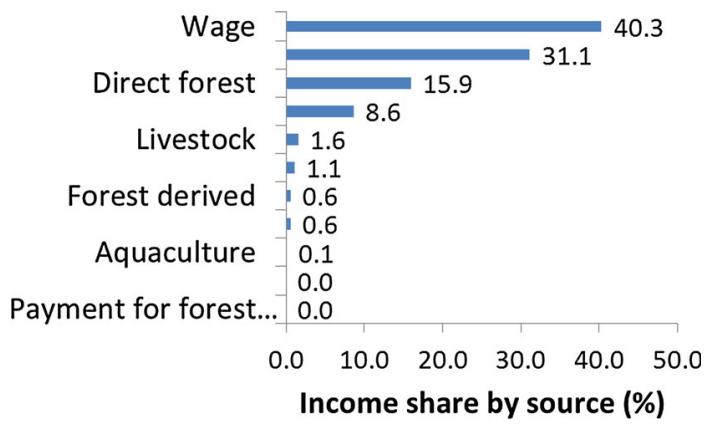




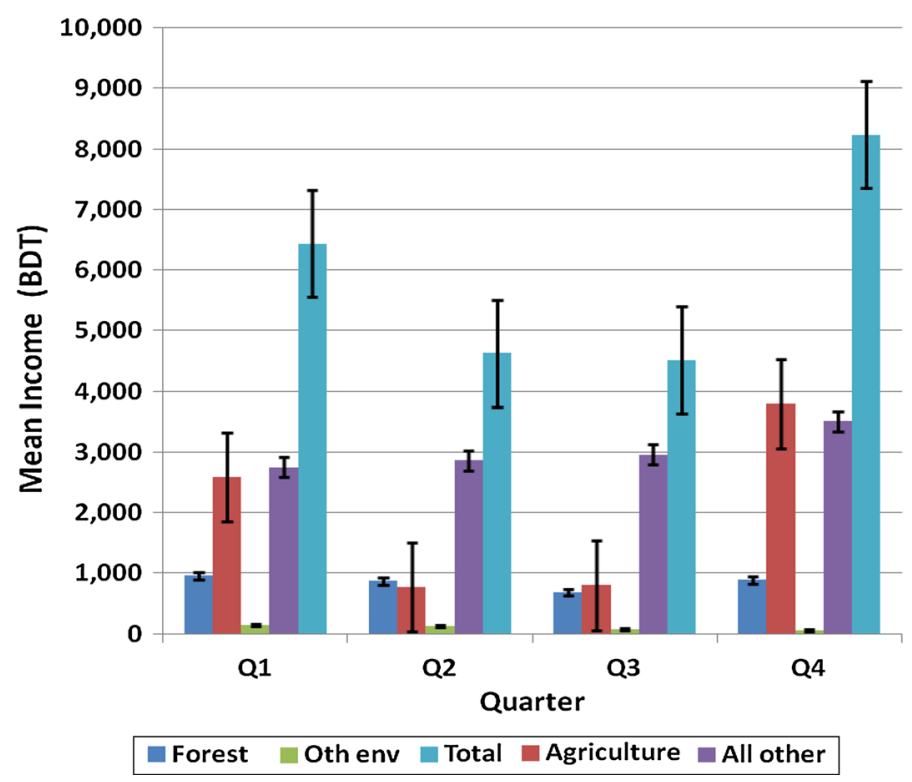

Fig. 3 Distribution of household income by season. Quarter 1(Q1) = September-November (wet and cool season), Q2 = December-February (winter season), Q3 = March-May (dry season), Q4 = JuneAugust (wet season). Note Other environmental income is obtained from fishing outside forests. (BDTUSD $1=$ BDT (Bangladesh Taka) 68.40 as of June 2012)

many people sell these products, which has increased demand for forest-based products.

Fuelwood, bamboo products, rattan, medicinal products and forest foods appear to be the key NTFP commodities in the study area. These commodities are important in maintaining local livelihoods. Fuelwood is the most important NTFP in overall economic terms, because most households remain dependent on fuelwood for heating and cooking. Bamboo shoots are also a primary source of income and of supplementary food for the households, which is especially important for helping to meet dietary shortfalls during the pre-harvest seasons of rice. Although vegetables and herbs are grown in home gardens, some people asserted that they can live without meat but not vegetables from forests-particularly Ivy Gourd (Coccinia grandis), bauhinia (Bauhinia purpurea) and Indian Pennywort (Centella japonica).

Historically, medicinal plants are an integral part of the primary health care systems of local communities in the study area. Plant remedies are prepared from various plant parts, including roots, bark, leaves, flowers and fruit. Deforestation at the CHT is depleting these critical subsistence resources and agroforestry can be a potential alternative.

Types and Nature of Agroforestry in the Study Area

Practicing agroforestry is an age old tradition of the farmers in the CHT. Recently their practices have been reinforced by the need for socio-economic and 
environmental sustainability. Three main agroforestry systems practiced in the study area are:

1. Agroforest integrated in a temporary phase of crop production within the existing forest matrix, without destroying or replacing it;

2. Rotational agroforest, in which the tree crop is established in the swidden, matures with the fallow vegetation, produces for a few decades and is renewed through a slash-and-burn cycle before being replanted in the same pattern;

3. Permanent forest culture established in perennial systems, which are integrally maintained over long periods of time, the decaying trees being individually replaced as needed. Over time, these cultivated forests increasingly resemble mature natural forests with a high, closed canopy, dense undergrowth and high levels of biodiversity.

In order to understand better the basic differences between the agroforestry models developed by farmers at the study area, it is useful to consider two main patterns. One is the ager model, the cultivation of ager (agricultural crops in the open field e.g. rice, wheat, maize, beans). In this model, cultivation involves a clear distinction between the cultivated field and the natural ecosystem, as well as between wild plants and domesticates. The cultivation patterns rest on homogenization, artificialization and specialization: a single, genetically homogeneous and even-aged plant population, which excludes 'weeds' and 'pests', and a clear focus on production of a single commodity. It involves heavy human control and highly specialized knowledge, and the plant combination depends totally on farmer's decisions. Artificialization culminates in resort to intensive chemical and mechanical inputs, associated with high energy consumption, aiming at maximum yields while overcoming natural constraints. The ager model reflects the productivist mentality, and it has deep influence of tree culture in the study area through forest plantations to replace shifting cultivation.

The alternative is the hortus model of forest culture, which involves development of tuber crops in homegardens. The garden retains the complexity of the natural ecosystem in order to accommodate the ecological exigencies of the cultivated plant. Diversity is the key theme in the 'garden model', which involves herbs, tuberous perennials, trees, lianas, and species and genotypes, and includes architectural as well as functional diversity. Management operates through individual treatment of plants, makes punctual interventions at key points in time, and takes full advantage of natural vegetation dynamics for production and reproduction. The garden is devised for multipurpose production as well as for optimal management of ecological and economic risks.

There are two important common principles of agroforestry in the study area, these being the principle of close 'integration' with agriculture, and particularly with the practices, logistics and dynamics of shifting cultivation, and the principle of 'multifunctionality'. Integration between agriculture and forest culture contrasts sharply with the vision of professional forestry, which sees agriculture and plantation forestry as worlds apart. In 'multifunctionality', smallholder agroforests, though designed for the production of products, are highly diverse in terms of both 
composition and utilization. This model, contrasts with the monocrop stands and single-purpose utilization of professional forest plantations.

\section{Suggested Agroforestry Model in the Study Site}

Drastic deforestation has taken place in the CHT. Based on the field observation two important agroforestry models can be suggested to protect tropical forest and to increase tree cover in at a landscape scale. One is multistrata agroforestry system for the agricultural and shifting cultivation fields close or adjacent to the depleted natural forest areas. The other is the complex fruit and timber-based conservation agroforest which can be established in the large depleted forest margins.

\section{Proposed multistrata agroforestry system}

This system is already practiced by some farmers in the study area, and is well suited for regeneration of forest vegetation in the shifting cultivation fields close to villages. This system is based on mangoes, jackfruit and timber trees together with vegetable and tuber species (Fig. 4; Table 1). In spite of the small size of the management units, the multistrata system is characterized by high species diversity and typically three or four vertical canopy strata, which results in intimate plant associations. The lower stratum can usually be partitioned into two layers, with the lower (less than $1.0 \mathrm{~m}$ height) dominated by eggplant, ginger and turmeric, and the higher (1.0-3.0 m) by bananas, papaya and lemons. The upper stratum is dominated by fruit and timber trees. Eggplant, papaya, bananas and lemons serve as intercrops during the first 4 years, after which the shade-tolerant species of ginger and turmeric are commonly planted under the trees, to maximize use of sunlight and improve soil protection.

\section{Proposed fruit and timber-based conservation agroforest}

The agrosilvicultural system with the mixture of crop and tree species in the study area is suggested to manage the large depleted landscapes (Fig. 5). The natural forest species-i.e. Dipterocarp trees, Litsea sp., shrubs and bamboo-could preserve hilltops by forming a mini-forest with hydrological functions. Acacia mangium and Litsea sp. can be planted next to the natural forest. Acacia timber is used for house repairs or sold to a processing factory, and the bark of Litsea sp. is easy to sell and can generate high financial returns. Fruit trees, including jackfruit and mangoes, can be planted in the remaining areas. For the purpose of food security, upland rice (Oryza sativa) and maize (Zea mays) can be intercropped with A. mangium, Litsea sp. and fruit trees for the first 6 years. Subsequently, shadetolerant pineapple (Ananas comosus) can be planted in these areas which can produce fruit after 1 year. Pineapples can also be planted with natural forest species on hilltops for the purpose of income generation and rational utilization of sunlight. Mungbean (Vigna radiata L.) and black beans (Phaseolus vulgaris) can be intercropped with fruit trees at the foot of the hills. These cash crops can generate high income as well as improve soil fertility. The legume contour hedgerows (Cassia siamea) can be established with fruit trees for soil erosion prevention and 


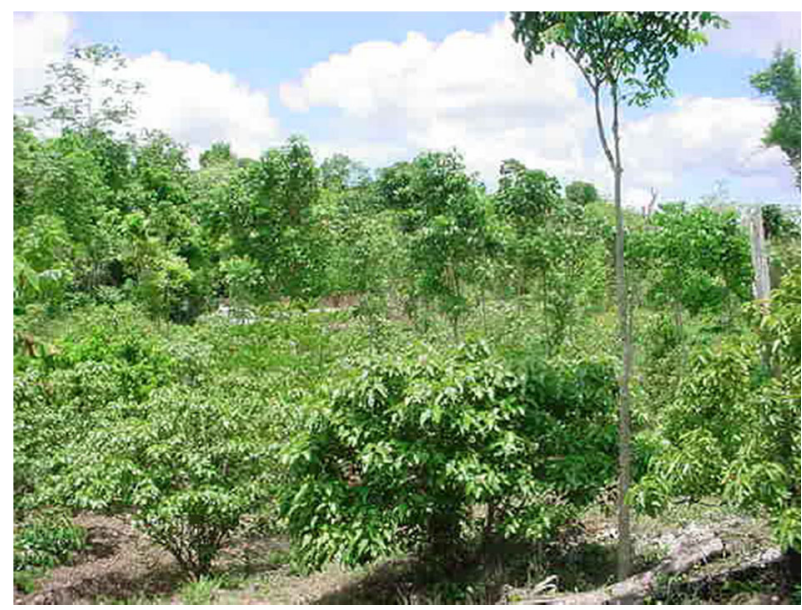

Fig. 4 Multistrata agroforestry system at the study area

Table 1 Suggested species combination in multistrata agroforestry ${ }^{\text {a }}$

\begin{tabular}{lccc}
\hline Species name & Spacing $(\mathrm{m})$ & $\begin{array}{l}\text { Number of } \\
\text { rows per acre }\end{array}$ & $\begin{array}{l}\text { Number of } \\
\text { plants per acre }\end{array}$ \\
\hline Mango (Mangifera indica) & $8 \times 8$ & 2 & 18 \\
Jackfruit (Artocarpus heterophyllus) & $8 \times 8$ & 2 & 18 \\
Acacia (Acacia mangium) & $8 \times 8$ & 2 & 18 \\
Lemon (Citrus limonum) & $3 \times 3$ & 9 & 316 \\
Papaya (Carcia papaya) & $2.5 \times 2.5$ & 5 & 192 \\
Banana (Musa spp.) & $2.5 \times 2.5$ & 5 & 192 \\
Eggplant (Solanum melongena) & $0.75 \times 0.75$ & 20 & 800 \\
Ginger (Zingiber officinale) & $0.50 \times 0.20$ & 80 & 40,000 \\
Turmeric (Curcuma domestica) & $0.50 \times 0.20$ & 80 & 40,000 \\
\hline
\end{tabular}

${ }^{a}$ Plant spacing varies greatly with site characteristics, e.g. between hills and plains

green manure supply. In addition, the branches of $C$. siamea, as well a Litsea sp. and A. mangium, are suitable for fuelwood.

Financial Analysis of Suggested Agroforestry Models

Taking 30 years of project life, the irrigation, pesticide and fertilizer, labour, and establishment costs are considered for the financial analysis (Table 2). The land market is underdeveloped in the study area, especially for land under traditional cultivation. However, as mentioned by MacDicken and Vergara (1990), there is no need to know land values if only marginal changes of land use are to be considered, as in this study.

Assuming a $10 \%$ annual discount rate yearly cash flow, Fig. 6 indicates that selected agroforestry models provide better income than shifting cultivation. The 


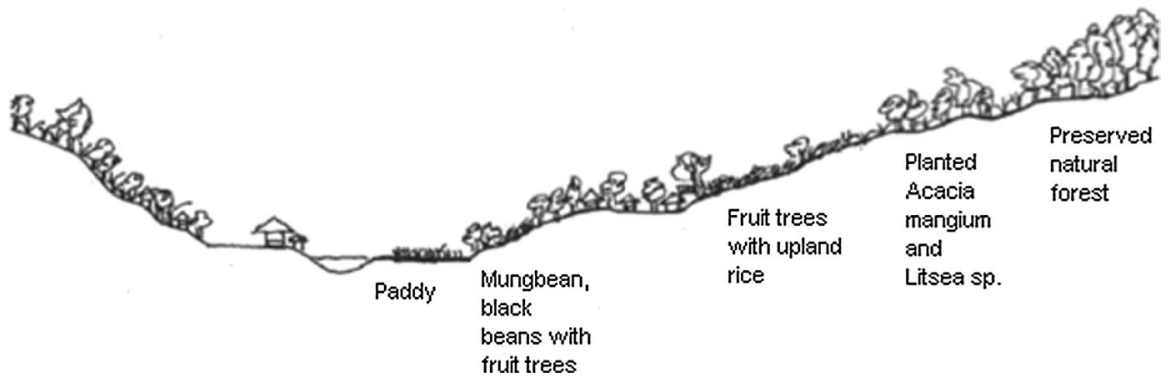

Fig. 5 Proposed vegetation sequence under the conservation agroforest model

Table 2 Yearly costs of three different cultivation systems (taka/acre-In this study no allowance was made for revenue foregone from ceasing the current landuse of swidden cultivation because the land productivity is very low. The research area is located in the eastern part of Bangladesh which is remote, with no viable alternatives to practicing agriculture)

\begin{tabular}{lllll}
\hline Type of operation & Year & \multicolumn{3}{l}{ Initial outlay and operating costs } \\
\cline { 3 - 5 } & & $\begin{array}{l}\text { Multistrata } \\
\text { agroforestry }\end{array}$ & $\begin{array}{l}\text { Fruit and timber based } \\
\text { conservation agroforest }\end{array}$ & $\begin{array}{l}\text { Shifting } \\
\text { cultivation }\end{array}$ \\
\hline $\begin{array}{l}\text { Establishment cost (land } \\
\text { preparation, sapling, seedling) }\end{array}$ & 0 & 47,880 & 46,500 & 12,569 \\
Labour cost & $0-10$ & 6,600 & 5,900 & 1,900 \\
& $11-30$ & 6,300 & 5,500 & 1,900 \\
Pesticide cost & $1-30$ & 277 & 230 & 304 \\
Fertilizer cost (NPK) & $1-6$ & 6,315 & 690 & 3,156 \\
& $7-10$ & 5,260 & 5,050 & 3,156 \\
& $11-30$ & 3,156 & 2,875 & 3,156 \\
Irrigation & $1-30$ & 15,784 & 12,200 & 3,683 \\
\hline
\end{tabular}

financial estimation is presented in Tables 2 and 3, and the agroforestry systems are predicted to generate better revenue than shifting cultivation. Considering the time lag between investment and first harvest, agroforestry may less attractive compared to other cropping. However, the agroforestry systems discussed here generates benefits quickly because of some understory crops. Overall, the analysis shows that agroforestry is by far and robustly the superior land use option, financially.

\section{Discussion}

In the tropics, timber extraction, and moreover industrial forest plantations, strictly exclude local farmers and their agricultural practices and vie with agriculture for land development (Marzuki 2003). Shifting agriculture is the main reason of deforestation in the research area, but the real symbiosis between shifting 


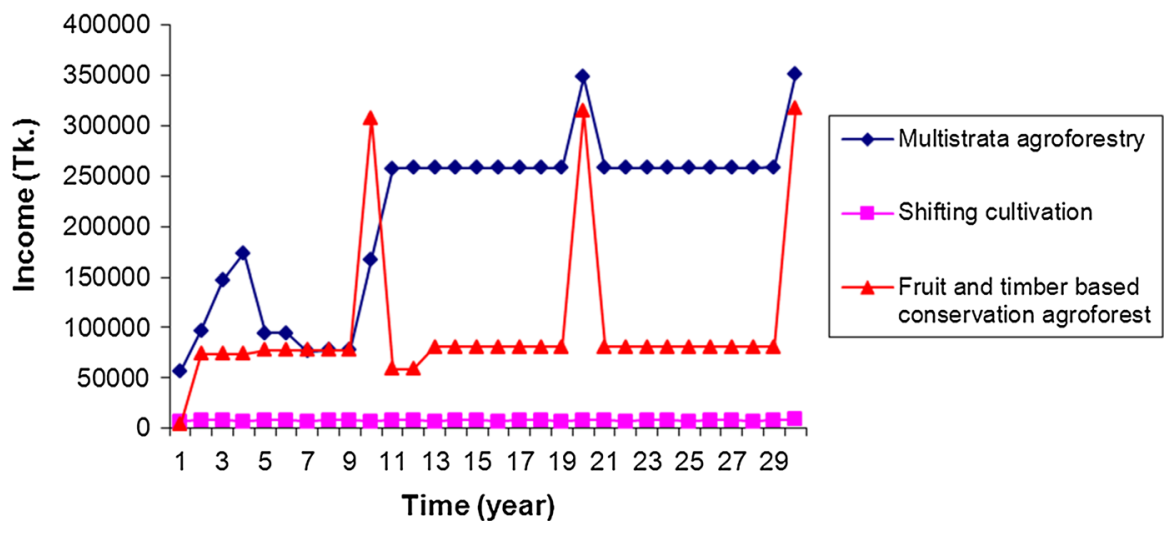

Fig. 6 Yearly discounted cash flow of the three cultivation systems (taka/acre)

Table 3 Yearly revenue of the three alternative cultivation systems (taka/acre)

\begin{tabular}{lcrrr}
\hline Cultivation system & Minimum & Maximum & \multicolumn{1}{c}{ Mean } & \multicolumn{1}{c}{ SD } \\
\hline Multistrata agroforestry & 63,000 & 387,000 & 237,300 & 92,919 \\
Shifting cultivation & 7,500 & 9,200 & 8,633 & 815 \\
$\begin{array}{l}\text { Fruit- and timber-based } \\
\text { conservation agroforest }\end{array}$ & 4,500 & 349,850 & 109,513 & 82,177 \\
\hline
\end{tabular}

agriculture and smallholder forestry is possible through agroforestry (Rahman et al. 2010). Hence the strong foundation of smallholder forest development is possible on shifting agriculture fields, and could deeply change the slash-and-burn agriculture to a forest culture.

Agroforestry itself comprises major social criteria of forest management, i.e. human input (labour), sharing of benefits, participation and conflict resolution (Poschen 2000). In that agroforestry needs labour input, benefits are shared within the community, and household members also participate in farm work. Agroforestry practices could secure tenure over farm areas and prevent illegal logging and forest encroachment thus resolving conflicts. However, tenure rules need to be reformed because tribal farmers use state land for their traditional cultivation, but do not have permanent or long-term rights to the land. Tenurial insecurity combined with frequent displacement cultivates a feeling of insecurity among the tribal farmers, discouraging investment in more productive land management, including fallow management. Tenurial insecurity also limits access to formal credit required for initial investments and for procuring the inputs needed to improve landuse practices.

Foresters usually assert that forest culture cannot be conceived on a small scale. However, small-scale forest culture is possible without increased costs or with acceptable financial returns if, and only if, it respects a close integration with slashand-burn systems and other existing agricultural practices (Michon 2005). The swidden field allows the planted forest to be established, developed and renewed. 
Slash-and-burn agriculture disappears when the silvicultural system has sufficiently matured. In return, the substitution of swidden by productive forest stands allows a rapid intensification of swidden agriculture without drastic changes in practices or dynamics. This intensification can be achieved through a smooth adaptation of practices, not through a painful revolution of the whole farming system. This adaptation obviously has important social consequences, because it avoids the marginalization and impoverishment of a whole class of farmers (Rahman et al. 2010). In this respect, the association of swidden and forest culture epitomizes a true complementary agroforestry system, where the association of 'agro' and 'forest' components occurs at the level of the farming system itself.

The introduction of forest culture increases labour productivity as well as global productivity on a per hectare basis of both the swidden-fallow system and the whole farming system. Unlike traditional fallows, planted forest provides cash and other productive outputs, without major constraints on land and labour utilization. Smallholder forests shelter species that can be further developed for market if the main production fails or if markets suddenly develop. New, financially interesting forest crops can easily be integrated into the system without disrupting its overall structure (Michon 2005). Examples are the multistrata agroforestry farmers who integrated various crop species under the tree canopy at the study site.

\section{Conclusion}

Small-scale tree growing through agroforestry in the degraded forest margins of the CHT is a viable strategy to protect natural forest and a mechanism for poverty reduction. Farmers can generate direct benefits from agroforestry, in the form of food and cash income, and receive considerable indirect environmental benefits.

Multifunctionality is emerging as a new concept for global agricultural and forestland development. It usually tends to be translated into landscape segregation, with some elements being defined for production, others for conservation, and still others for restoration. The validity of a close integration of various functions in a single system is often questioned. However, multifunctionality can be achieved through smallholder forest culture which can integrate various functions in a single system, that can manage degrading tropical forest and maintain livelihoods in a sustainable way.

Acknowledgments This research is a part of a global project of CIFOR, known as the Poverty and Environment Network (PEN). The authors would like to thanks Arild Angelsen, Bruce Campbell, Jette Bredahl Jacobsen, Ramadhani Achdiawan and Ronnie Babigumira for their support and guidance. The authors are also thankful to the Department of Sociology, University of Rajshahi, Bangladesh which supported this research. Many thanks are also extended to the farmers at the study site where field survey was undertaken, who share their precious time, thought and concerns.

\section{References}

Angelsen A, Helle OL, Jens FL, Carsten SH, Sven W (2011) Measuring livelihoods and environmental dependence: methods for research and fieldwork. Earthscan, London 
Arya LM (2000) Final consultancy reports on hill agriculture. Agricultural Research Management Projects (ARMP), Bangladesh Agricultural Research Institute, Dhaka, Bangladesh

Asian Development Bank (ADB) (2001) Chittagong hill tracts region development plan. ADB TA No. 3328, Dhaka, Bangladesh

Audsley E, Brander M, Chatterton J, Murphy-Bokern D, Webster C, Williams A (2009) How low can we go? An assessment of greenhouse gas emissions from the UK food system and the scope to reduce them by 2050. FCRN-WWF-UK, London

Bangladesh Bureau of Statistics (BBS) (2007) Statistical yearbook of Bangladesh. Ministry of Planning, Dhaka

Bangladesh Forest Department (BFD) (2008) National forest and tree resources assessment 2005-2007. Ministry of Forestry, Dhaka

Bryant RL (1997) The political ecology of forestry in Burma. C. Hurst \& Co. Ltd., London

Elevitch C, Wilkinson KM (1998) A guide to orchard alley cropping for fertility, mulch and soil conservation. AgroForester, Honolulu

Food and Agriculture Organization of the United Nations (FAO) (2005) Global forest resources assessment 2005: Bangladesh country report. FAO, Rome

Gafur A (2001) Effects of shifting cultivation on soil properties, erosion, nutrient depletion, and hydrological responses in small watershed of the Chittagong Hill tracts of Bangladesh. Ph.D. Dissertation, The Royal Veterinary and Agricultural University, Copenhagen

Huq MM (2000) Government institutions and underdevelopment: a study of the tribal people of Chittagong hill tracts, Bangladesh. Dhaka University, Dhaka

Leakey RRB, Weber JC, Page T, Cornelius JP, Akinnifesi FK, Roshetko JM, Tchoundjeu Z, Jamnadass R (2012) Tree domestication in agroforestry: progress in the second decade. In: Nair PKR, Garrity DP (eds) The future of agroforestry. Springer, New York, pp 145-173

MacDicken KG, Vergara NT (1990) Agroforestry: classification and management. Wiley, New York

Mai PT (1999) Socio-economic analysis of shifting cultivation versus agroforestry system in the upper stream of lower mekong watershed in Dak Lak province. MA thesis in Economics of Development, National University-HCMC, Viet Nam and Institute of Social Study (ISS), The Hague, The Netherlands

Marzuki Y (2003) Dare' ampiri: wanatani khas maros, Sulawesi Selatan. M.Sc. Thesis, Universitas Indonesia, Jakarta

Michon G (2005) Domesticating forests: how farmers manage forest resources. IRD, CIFOR and ICRAF, Bogor

Nath TK, Inoue M, Myant H (2005) Small-scale agroforestry for upland community development: a case study from Chittagong hill tracts, Bangladesh. The Japanese Forest Society and Springer-Verlag, Tokyo

Niemeijer D (1996) The dynamics of african agricultural history: is it time for a new development paradigm? Dev Change 2(1):87-110

Poschen P (2000) Social criteria and indicators for sustainable forest management: a guide to ILO texts. Working Paper 3, International Labour Office (ILO) and Deutsche Gesellschaft für Technische Zusammenarbeit (GTZ), Eschborn, Germany and Geneva

Rahman SA, Rahman F (2011) Managing forest at a landscape scale: reconciling smallholder forest culture in the uplands of eastern Bangladesh. Lap Lambert Academic Publishing, Saarbrucken

Rahman SA, Rahman MF, Codilan AL, Farhana KM (2007) Analysis of the economic benefits from systematic improvements to shifting cultivation and its evolution towards stable continuous agroforestry in the upland of eastern Bangladesh. Int For Rev 9(1):536-547

Rahman SA, Fitriana YR, Walz K (2010) Forested farmlands: a real agroforestry symbiosis from shifting cultivation and its evaluation towards stable contentious agroforestry in south and south-east Asia. In: Proceedings of XXIII IUFRO World Congress, 23-28 August, Seoul, Republic of Korea

Shoaib JU, Mostafa G, Rahman M (1998) Soil erosion hazard in Chitttagong hill tracts: a case study. Annual report, Soil Resources Development Institute, Dhaka, Bangladesh

United Nations Development Programme (UNDP) (1994) A fork in the path, human development choices for Bangladesh. Pioneer Printing Press Ltd., Dhaka 